\title{
Neologia, terminologia e lexicultura \\ a língua portuguesa em situação de contacto de línguas
}

Maria Teresa Lino* Alexandre Mavungo Chicuna**

Ana Pita Grôz ${ }^{* * *}$

Daniel Medina****

RESUMO: A temática central deste artigo é a neologia terminológica na Língua Portuguesa em situação de contacto de línguas. Em consequência das novas propostas da Socioterminologia e da Terminologia Cultural, a nossa investigação incide, hoje, sobre a neologia terminológica, a metáfora terminológica, os vários tipos de variação terminológica aos quais se associam aspectos de lexicultura, presentes em muitos neónimos e termos científicos. Todos estes fenómenos linguísticos têm uma grande incidência na descrição terminológica, na lexicografia de especialidade, na tradução e no ensino-aprendizagem das línguas de especialidade.

Palavras-chave: Lexicultura; neologia terminológica; contacto de línguas.

ABSTRACT: The central theme of this article is the terminological neology in the Portuguese in language contact situations. As a result of new proposals of Socioterminology and Cultural Terminology, actually our research focuses on the terminological neology, terminological metaphor, different types of variation in terminology to which associate with lexicultural aspects present in neologism and scientific terms. All these linguistic phenomena have a great effect in the terminological description, in special purpose lexicography, in translation and in teaching and learning of specialized languages.

Keywords: Lexiculture; terminological neology; language contact.

\footnotetext{
Universidade Nova de Lisboa, Portugal. E-mail: tlino@mail.telepac.pt

** Universidade Agostinho Neto, Angola. E-mail: makikuna@hotmail.com

*** Universidade Agostinho Neto, Angola. E-mail: anpigromasil@hotmail.com

**** Universidade de Cabo Verde, Cabo Verde. E-mail: danielmedina@portugalmail.pt
} 


\section{0}

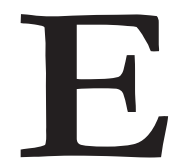

ste artigo tem como temática central a neologia terminológica na Língua Portuguesa, em situação de contacto de línguas. A Língua Portuguesa não cessa de evoluir, nos vários espaços lusófonos, onde coabita com outros tipos de línguas. Os critérios de identificação dos fenómenos de neologia, tradicionalmente aceites, são insuficientes para dar conta desta nova realidade; os corpora textuais e lexicográficos, os bancos de terminologia internacionais e os documentos produzidos por instituições nacionais de normalização continuam a ser parâmetros importantes, mas não conseguem contribuir de uma forma clara e inequívoca na delimitação de um neologismo, em consequência da dinâmica da Língua nos vários países, com culturas específicas.

Os neónimos e os termos, unidades lexicais especializadas das ciências e das técnicas, representam os conceitos, que, em muitas áreas do conhecimento, não têm um carácter internacional, mas são sensíveis à cultura de um determinado país ou comunidade. O conceito e o termo apresentam elementos de cultura; frequentemente, na terminologia médica ou na terminologia jurídica, por exemplo, um termo é caracterizado por semas que traduzem propriedades do conceito relativas a aspectos da cultura de uma sociedade.

Lexicultura, neologismo terminológico criado por Robert Galisson ${ }^{1}$, nos finais da década de oitenta, designa os elementos de cultura presentes no léxico, quer no subsistema da língua corrente, quer nos subsistemas das línguas de especialidade. Os fenómenos de lexicultura estão presentes nas macro e micro-estruturas do dicionário de especialidade, instrumento indispensável aos especialistas das diferentes áreas do conhecimento, aos tradutores e ao ensino-aprendizagem da língua materna e das línguas estrangeiras para fins específicos.

A Linguística de corpus veio problematizar a relação significação/sentido numa perspectiva de semântica textual. Esta nova abordagem textual, designada de Terminologia textual, assim como a descrição dos fenómenos de variação em contexto constituem uma transgressão aos princípios clássi-

1 Para além de lexicultura, recordamos apenas alguns neologismos terminológicos, criados por este autor e que, hoje, estão completamente assimilados à metalinguagem de várias disciplinas (Lexicologia, Lexicografia, Terminologia e Didactologia das línguas-culturas): lexicometodologia, lexicodidactologia, temas de predilecção, carga cultural partilhada (CCP), operações verbo-culturais (OCV), palimpsestes verbo-culturais (PVC), pragmática lexicultural, banalização lexical, lexicografia de aprendizagem, lexicografia de geometria variável, dicionários de lexicultura, autodicionário. 
cos da terminologia wusteriana que privilegiava a tríade termo/conceito/ referente, preconizando a monossemia do termo científico e técnico. Em consequência destas novas perspectivas e das novas propostas da Socioterminologia e da Terminologia Cultural, a nossa investigação incide, hoje, sobre a neologia terminológica, a metáfora terminológica, os vários tipos de variação terminológica aos quais se associam aspectos de lexicultura, presentes em muitos neónimos e termos científicos. Todos estes fenómenos linguísticos têm uma grande incidência na descrição terminológica, na lexicografia de especialidade, na tradução e no ensino-aprendizagem das línguas de especialidade.

Paralelamente a estas particularidades linguísticas, temos um interesse especial pelo estudo da variação fonomorfossintáctica e da variação semântica, isto é, a polissemia ${ }^{2}$, a sinonímia ${ }^{3}$, a reformulação terminológica ${ }^{4}$ e a fraseologia ${ }^{5}$, fenómenos que participam muitas vezes na neonímia ${ }^{6}$ e que são, por vezes, portadores de elementos de lexicultura.

\section{0}

Nestes últimos anos, a metáfora tem sido objecto de investigações não apenas em linguística (cf. Oliveira, I. 2005 e 2009), mas também em numerosos trabalhos em ciências cognitivas, em neurolinguística e em antropologia.

A metáfora é necessária à comunicação entre línguas e culturas, participando na preservação da diversidade das línguas e das culturas veiculadas pelas diferentes línguas; de uma cultura para outra, existem numerosas correlações e associações que determinam e explicam os fundamentos das estruturas metafóricas. A metáfora de especialidade ou metáfora terminológica é, frequentemente, o resultado de uma construção da significação carregada de valores culturais. A nossa visão do mundo determina o modo de classificar e de ordenar aquilo que conceptualizamos.

A metáfora "não é apenas uma questão de linguagem, mas também uma estrutura conceptual” (G. Lakoff et M. Johnson 1985: 247); é um mecanismo fundamental para a compreensão das experiências humanas. O papel

\footnotetext{
Cf. GARCIA, Lurdes (2003).

Cf. CONTENTE, Madalena (2003) e (2008).

Cf. CONCEIÇÃO, M. Célio (2001).

Cf. GONÇALVES, Sónia (2003).

Cf. LINO, Teresa (2003).
} 
da metáfora pode ser interpretado como a percepção de correlações entre vários domínios de experiência. Catherine Détrie (2001: 172) faz notar que a semelhança “n'est jamais préexistante au processus métaphorique, mais est au contraire créée par la métaphore. La relation de similitude qu'on peut percevoir dans la métaphore n'est pas une relation d'objet à objet, mais de domaine d'expérience à domaine d'expérience. La métaphore dit donc une compréhension du monde par l'interaction de praxis".

Segundo Lakoff et Johnson (1985: 242), a nossa experiência é estruturada "de manière cohérente en termes de gestalts qui ont émergé directement de l'interaction avec (et dans) notre environnement". Interpretamos o mundo de uma maneira metafórica quando utilizamos uma gestalt pertencente a um domínio de experiência para estruturar a nossa experiência noutro domínio.

\section{1}

Privilegiamos uma abordagem da metáfora enquanto instrumento intercultural. Esta perspectiva deve ter em conta a diversidade cultural, no processo de elaboração de dicionários que integram termos metafóricos enquanto produtos linguísticos culturalmente integrados. Consequentemente, é necessário um novo método de trabalho que tem por base uma abordagem cultural da Terminologia.

No âmbito dos processos de criação terminológica, a metáfora pode dar lugar a um método de criação neonímica uma vez que tem por base realidades culturais. Nesta óptica, estudamos a metáfora terminológica com uma base cultural de conceptualização e fonte de neologismos terminológicos.

Apresentamos nas alíneas que se seguem algumas metáforas terminológicas em que existem elementos lexiculturais: a) alguns novos termos foram recentemente dicionarizados, mas são ainda sentidos como novos e com um carácter neológico, em Português, no domínio da Senologia (cf. Dicionário Terminológico da Senologia); b) metáforas terminológicas mortas, isto é, termos já enraizados e dicionarizados em Cardiologia, em Português, Francês e Inglês (cf Métaphores en Cardiologie); c) metáforas terminológicas em Quimbundo, Quiyombe e Caboverdiano, termos com um carácter neológico em fase de dicionarização.

\section{2}

O Dicionário Terminológico de Senologia, elaborado por Lurdes Garcia a partir de corpora plurilingue (português, francês, inglês e espanhol) apresenta um gran- 
de número de neónimos (neologismos científicos) na nomenclatura e nas definições lexicográficas.

A partir dos contextos extraídos dos corpora podem ser analisados vários fenómenos de variação terminológica (polissemia nominal, sinonímia, neologia semântica por polissemização), mas também a metáfora e a metonímia, processos muito importantes da neologia semântica.

Os novos aspectos conceptuais manifestam-se, no plano linguístico, através de neologismos semânticos criados por polissemizações de diferentes tipos. Mencionamos apenas alguns exemplos.

Assim, em neónimos dos subdomínios da Cirurgia e da Senologia, a polissemia opera por extensão de sentido:

\section{Ex.: abordagem}

"Zona delimitada e técnica escolbidas para a incisão cirúrgica que permitem o acesso à estrutura a operar";

\section{Ex.: reconstrucão}

"Definição da ordem e tempos para realização das várias etapas de reconstrução mamária's.

Os neónimos "abordagem" e "reconstrução" apresentam polissemias resultantes da aquisição de semas suplementares.

Noutro tipo de neónimo também do subdomínio da Cirurgia e da Senologia observamos uma relação metonímica:

\section{Ex.: reducão}

"Redução do volume mamário ou de um tecido tumoral através de um processo de cirurgia plástica"

Este fenómeno não se limita ao caso específico à elipse "redução", mas estende-se igualmente aos termos complexos: "mamária", "mamoplastia de redução", "cirurgia plástica de redução mamária"10.

\footnotetext{
Cf. Extracção de contextos do corpus de Senologia.

Cf. Extracção de contextos do corpus de Senologia.

Cf. Extracção de contextos do corpus de Senologia.

10 Cf. Garcia, L. 2003. Dicionário Terminológico da Senologia.
} 
Observamos, igualmente, em neónimos do subdomínio da Cirurgia plástica, polissemias que reflectem uma relação metafórica:

Ex.: retalho

"Porção de tecidos separados cirurgicamente do seu lugar de origem, mas ao qual ficam ligados por um pediculo vascularizado que os alimenta, sendo mobilizados para outra zona com fins reconstrutivos".

Ex.: retalho livre

"Porção de tecidos com uma vascularização axial que são completamente separados do seu local anatómico, inclusive com secção do seu pedículo, transpostos para uma nova zona e ai o sen pedículo suturado a vasos da região".

Nestes dois exemplos, verificamos que certos semas não são objecto de uma denominação explícita; trata-se de duas denominações metafóricas; os semas com uma relação metafórica revelam-se através da análise do contexto definitório.

Apresentamos alguns ecrãs do Dicionário Terminológico de Senologia, em versão CD-Rom.

Exemplo: neónimo - metáfora terminológica: retalho

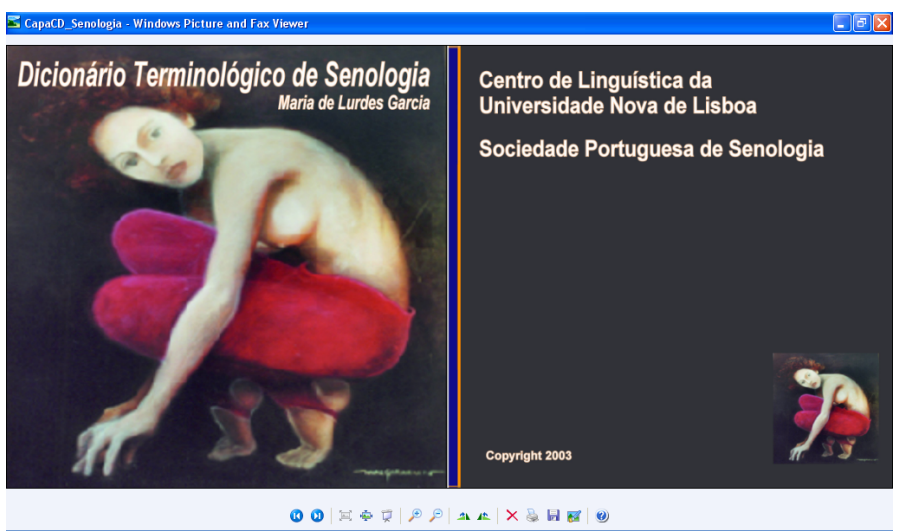


Exemplo: neónimo - metáfora terminológica: mamoplastia de redução pela técnica do retalho em avental
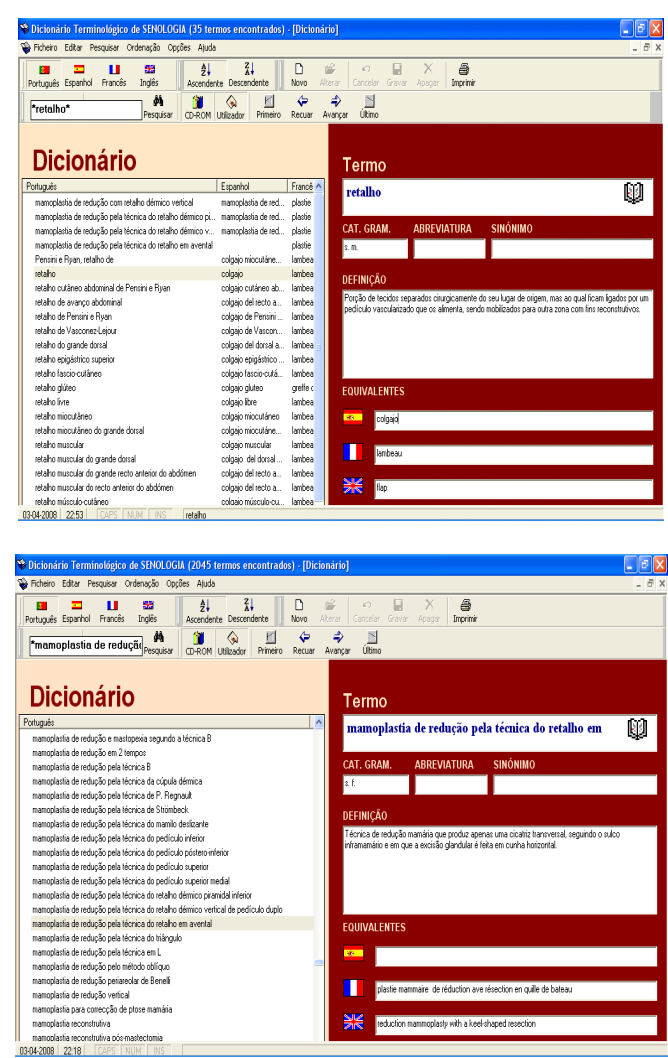

Exemplo: neónimo - metáfora terminológica: calcificacõoes chávena de chá

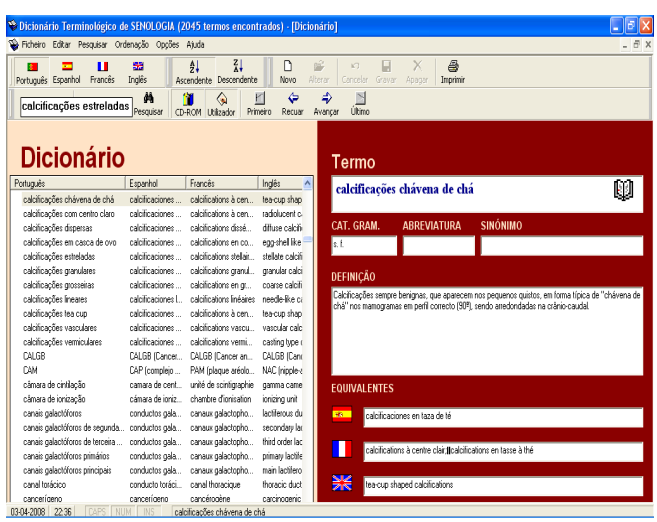


194 Maria Teresa Lino; Alexandre Mavungo Chicuna; Ana Pita Grôz; Daniel Medina

Os três últimos ecrãs apresentam neónimos, termos complexos com relações metafóricas, portadores de uma componente lexicultural: retalho, mamoplastia de redução pela técnica em avental e calcificaçoes em chávena de chá.

A metáfora não é apenas uma figura de estilo, mas um processo $\operatorname{cognitivo~}^{11}$ subjacente à criação de muitos termos científicos. Mencionamos seguidamente outros exemplos de termos, metáforas terminológicas, no domínio da Cardiologia ${ }^{12}$ :

\section{Termo em português: ruído do pião \\ Equivalente francês: bruit du diable \\ Equivalente inglês: nun's murmur}

Este termo e os seus equivalentes em francês e em inglês são exemplos de metáforas da Cardiologia em que os elementos lexiculturais estiveram presentes no processo da sua denominação; são metáforas terminológicas extraídas do CD-Rom Les métaphores en cardiologie, dicionário terminológico bilingue construído em espelho entre o Francês e o Português.

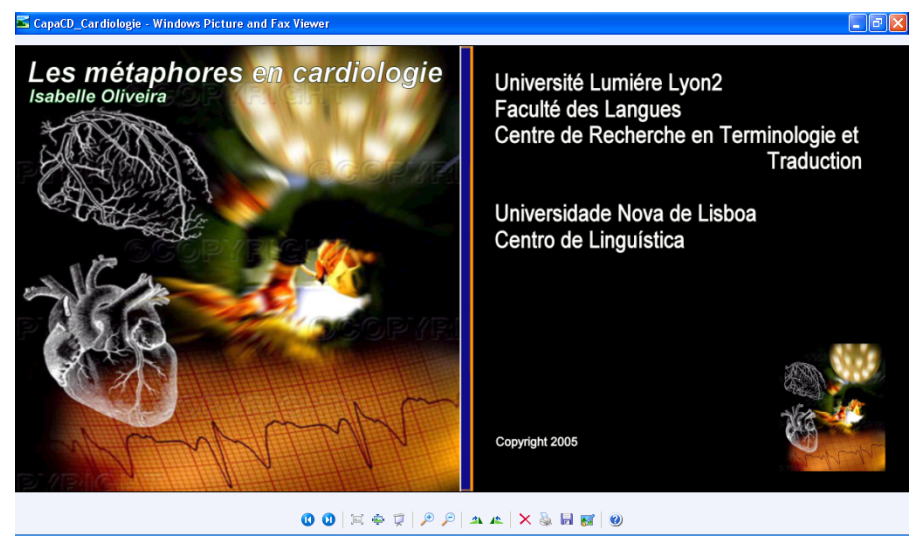

11 OLIVEIRA, I. 2005a.

12 OLIVEIRA, I. 2005b. Les métaphores en cardiologie. CD-Rom. Université Lumière Lyon 2, Universidade Nova de Lisboa 


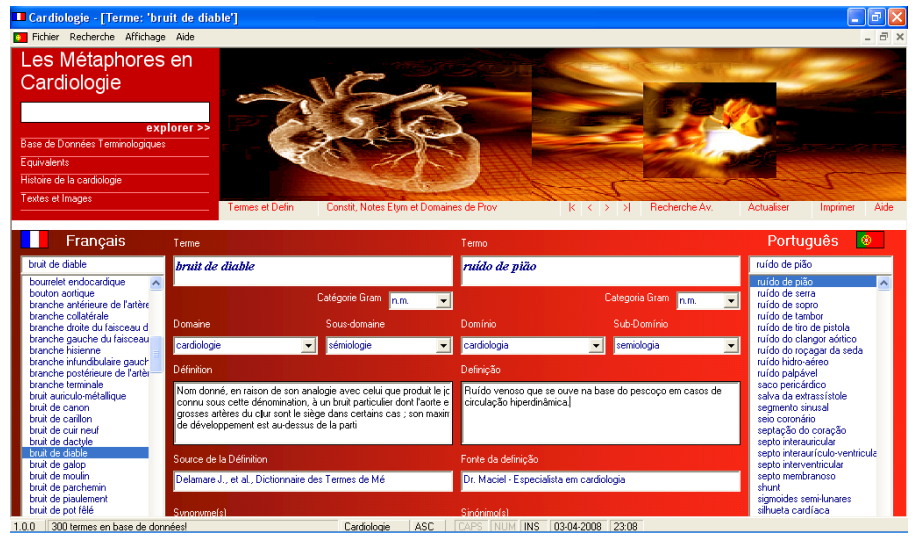

\section{3}

Existem conceitos africanos, no domínio da Medicina Tropical, que são inexistentes em Portugal; as terminologias da malária, da tuberculose, do cancro, da senologia integram termos específicos e termos que apresentam particularidades conceptuais, diferentes das que caracterizam as terminologias destes domínios científicos em português de Portugal.

Estão em fase de elaboração dois Dicionários Terminológicos Bilingues de Português com línguas bantu, que têm como objectivo dicionarizar conceitos e termos médicos africanos, onde são, frequentemente, observáveis as componentes culturais do conceito.

Assim, passamos a apresentar o modelo do Dicionário Bilingue Português - Quimbundo do domínio da Medicina e da Saúde que está a ser desenvolvido por Ana Pita Grôz da Universidade Agostinho Neto - ISCED (Luanda). A sistematização da Terminologia da Medicina e da Saúde em paralelo com uma Língua Bantu, neste caso, o Quimbundo, pode constituir um trabalho muito útil aos médicos e aos profissionais da saúde na comunicação com os doentes. Por outro lado, este Dicionário contribuirá para a descrição e fixação da Língua Quimbundo, que possui um grande número de termos médicos ainda não dicionarizados. 


\section{DICIONÁRIO BILINGUE PORTUGUÊS-QUIMBUNDO MEDICINA E SAÚDE}

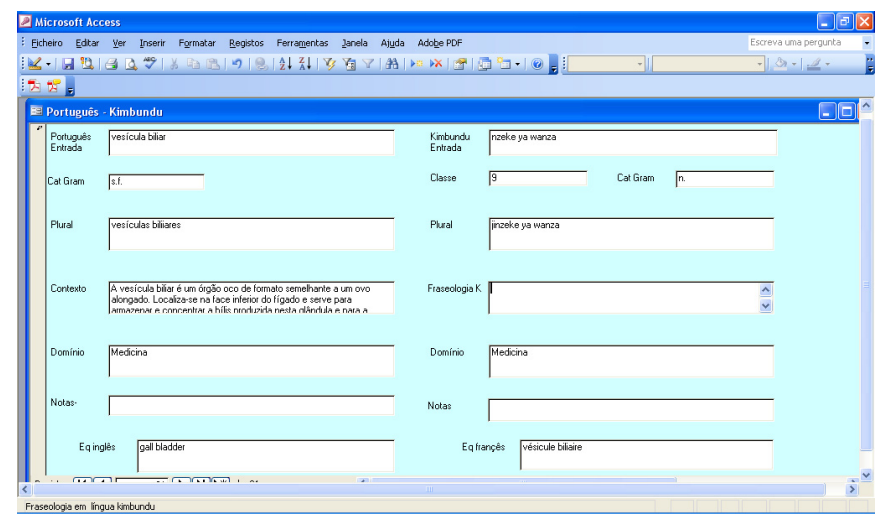

Neste momento, Alexandre Chicuna está a elaborar um Dicionário Bilingue Português-Quiombe nos domínios da Medicina e da Saúde, que tem por objectivo uma descrição da terminologia dessas áreas em Português e em Quiombe; trata-se de um trabalho que deverá ter um grande impacto social, muito em especial na comunicação dos médicos e dos profissionais da saúde com os pacientes que desconhecem o Português.

\section{DICIONÁRIO BILINGUE PORTUGUÊS-QUIOMBE MEDICINA E SAÚDE}

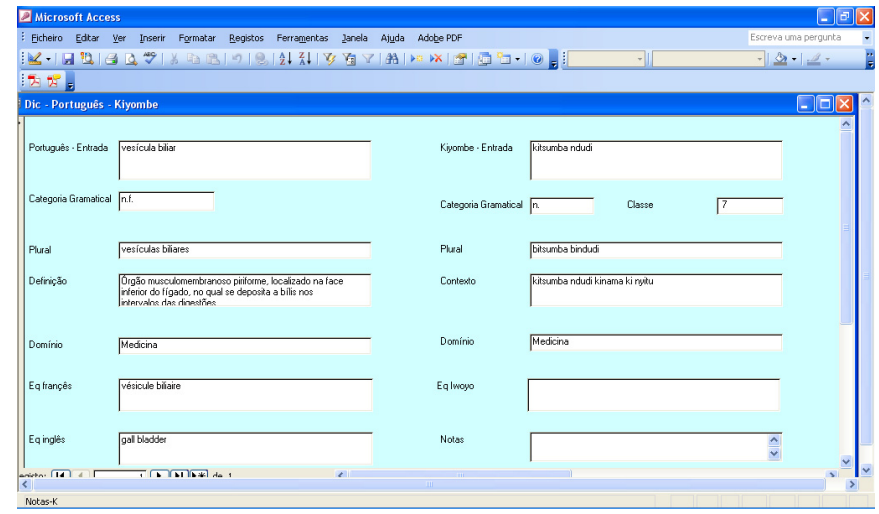


Assim, trabalhamos com a Língua Portuguesa em situação de contacto de línguas africanas: duas línguas bantu de Angola, o Quimbundo e o Quiombe e a língua de Cabo Verde, o Caboverdiano.

Estas investigações têm por base corpora abertos segundo os critérios preconizados pela Linguística de corpus. São corpora representativos de diferentes tipos de discursos e de níveis de especialização. Sempre que é possível constituímos corpora tematicamente paralelos bilingues ou multilingues (português, e outras línguas: o Quimbundo, o Quiombe e o Caboverdiano). A constituição destes corpora implica um trabalho de recolha e de análise de dois tipos de corpora: corpora escritos e corpora orais. Os corpora escritos são constituídos por textos altamente especializados: obras e revistas científicas e teses de doutoramento. Uma vez que as línguas africanas seleccionadas em função desta investigação possuem muito poucos textos escritos em Medicina, decidimos trabalhar a partir de corpora orais recolhidos junto de profissionais de saúde. Estes corpora são, em parte, transcritos de modo a permitirem uma análise dos enunciados e a identificação de metáforas terminológicas.

Os corpora textuais são trabalhados com a ajuda de hipertextos importantes para a extracção de termos, de neónimos e de metáforas terminológicas; são também indispensáveis na detecção de fenómenos de variação terminológica (polissemias, sinónimos) e variantes diatópicas relativas aos usos próprios de cada país.

\section{4}

Os fenómenos estudados são, por um lado a denominação metafórica morta enraizada na experiência do locutor nativo e por outro a denominação metafórica neológica, a sinonímia e a equivalência interlinguística. Sublinhamos que estes fenómenos apresentam relações de interdependência entre si.

A título de exemplo, apresentamos algumas metáforas terminológicas em Quimbundo, Quiombe e em Caboverdiano:

a) metáforas terminológicas na Língua Quimbundo mbangala [bengala do corpo] - equivalente português: esqueleto dilonga dya kysuxi [ prato do ombro] - equivalente português: omoplata dilonga dya ipumuna [prato do joelho] - equivalente português: rótula mala [abdómen] - equivalente português: abdómen petho dya nzila [peito que chia]: bronquite 
b) metáforas terminológicas na Língua Quiyombe: disoko dikulu [fruta da perna] - equivalente português: coxa kilezi [o menor] - equivalente português: cordão umbilical kivumu [barriga-gestação] - equivalente português: gestação. lulonga lu dikuma [prato do joelho] - equivalente português: rótula lulonga lu divangiti [prato do ombro] - equivalente português: omoplata mwanzi disafi [raiz do pulmão ] - equivalente português: aorta nzila mwanzi [raiz do caminho] - equivalente português: canal arterial

c) metáforas terminológicas na Língua Caboverdiana: cortamento de barriga - equivalente português: cólica djunta [junta - equivalente português: articulação petu fechado [peito fechado] - equivalente português: bronquite

São termos e neónimos metafóricos de diferentes níveis de especialização que têm subjacentes elementos de cultura, elementos lexiculturais.

\section{0}

Concluindo, num plano geolinguístico, esta investigação tem por objectivo a elaboração de bases terminológicas e de dicionários terminológicos multilingues, recursos terminológicos indispensáveis aos profissionais da saúde, aos redactores técnicos, tradutores, professores de línguas de especialidade; a metáfora terminológica constitui, frequentemente, uma motivação na aprendizagem das línguas-culturas dos estudantes em Medicina, em particular.

Por outro lado, esta investigação tem por objectivo criar recursos terminológicos úteis aos investigadores que se interessam por Terminologia Cultural, por Lexicultura, e pela metáfora terminológica nas línguas de especialidade.

Por último, sublinhamos a importância do conceito de lexicultura que se tem revelado importantíssimo da descrição lexicológica, lexicográfica e terminológica, quer numa perspectiva monolingue, bilingue ou multilingue. Os elementos lexiculturais estão presentes em muitos termos das nomenclaturas e nas definições lexicográficas.

A elaboração de recursos de lexicografia de aprendizagem em língua corrente ou em língua de especialidade deverá ter sempre subjacente este conceito, muito em especial, hoje, à luz das teorias da Terminologia Cultural que sublinham o facto de o conceito científico ser sensível aos elementos de cultura da comunidade científica que o utiliza. 
Referências bibliográficas

BÉJOINT, H.; THOIRON, P. 2000. Le sens en terminologie, Lyon: Presses Universitaires de Lyon, Travaux du Centre de Recherche en Terminologie et Traduction, Université Lumière - Lyon 2.

BENTO, J. R. 2007. Da construção do corpus à construção de uma ontologia e base de conhecimentos terminológicos. Tese (Doutoramento) - Universidade Nova de Lisboa.

CHICUNA, A. 2003. Léxico Português-Kyiombe do Corpo Humano: particularidades dos morfemas flexionais. Tese (Mestrado). Universidade Nova de Lisboa.

2005. A situação em Angola. Os termos do coberto arbóreo no Mayombe (Cabinda). Terminómetro - A terminologia em Portugal e nos países de lingua portuguesa em África número especial, União Latina. p.78-82.

CHICUNA, A. 2009. Tratamento Lexicográfico dos Portuguesismos em Kyiombe. Tese (Doutoramento). Universidade Nova de Lisboa.

CONCEIÇÃO, M. C. 2001. Termes et Reformulations. Tese (Doutoramento). Universidade Nova de Lisboa.

CONCEIÇÃO, M. C. (2005) Concepts, termes et reformulations. Lyon: Presses Universitaires de Lyon.

CONDAMINES, A. 2005. Sémantique et corpus. Paris: Hermes /Lavoisier.

CONTENTE, M. 2008. Terminocriatividade, sinonimia e equivalência interlinguistica em Medicina. Tese (Doutoramento). Universidade Nova de Lisboa. Lisboa: Colibri.

COSTA, R. 2001. Pressupostos teóricos e metodológicos para a extracção automática de unidades terminológicas multilexémicas. Tese (Doutoramento). Universidade Nova de Lisboa.

COSTA, R.; SILVA, R. 2004. The verb in the terminological collocations. Contribution to the development of a morphological analyser.,Proceedings LREC 2004 - IV International Conference on Language Resouces and Evaluation. p.1531-34.

DECHAMPS, C. 2006. Problemáticas do ensino/aprendiragem das colocacões de uma lingua de especialidade a um público alófono: o caso do francês jurídico a aprendentes portugueses. Tese (Mestrado). Universidade Nova de Lisboa.

DÉTRIE, C. 2001. Du sens dans le processus métaphorique. Paris: Honoré Champion.

GALISSON, R. 1981. Approches communicatives et acquisition des vocabulaires (du concordancier à l'autodictionnaire personnalisé). Bulletin Cila 13-50.

GARCIA, L. 2003. Dicionário Terminológico de Senologia, CD-ROM. Lisboa: Centro de Linguística da Universidade Nova de Lisboa e Sociedade Port. de Senologia.

GARCIA, L. 2003. O semantismo referencial nos processos terminogénicos da terminologia da Senologia. Tese (Doutoramento). Universidade Nova de Lisboa.

GONÇALVES, S. 2003. Reflexões em torno da neonímia: fraseologia e colocações neonímicas. Tese (Mestrado). Universidade Nova de Lisboa.

GRAÇA, E. 2010. Terminologia do Direito Processual Civil em Cabo Verde. Tese (Mestrado). Universidade Nova de Lisboa.

GRÔZ, A. P. 2008. Dicionário bilingue de Medicina (Português-Kimbundu). Tese (Mestrado). Universidade Agostinho Neto.

HEITOR, O. 2006. e-Dicionário de especialidade: a fraseologia denominativa. (Mestrado). Universidade Nova de Lisboa. 
LAKOFF, G.; JOHNSON, M. 1985. Les métaphores dans la vie quotidienne. Paris: Les Editions de Minuit.

LINO, T. 1991. Terminodidáctica: uma nova área de investigação. In: Actas do VII Encontro da Associação Portuguesa de Linguistica. Lisboa. p.14.

2001. De la néologie à la lexicographie spécialisée d’apprentissage. Cahiers de Lexicologie 78 - Hommage à Robert Galisson. 139-45.

2003. Lexicographie de spécialité Plurilingue - Médecine et Pharmacologie en Langues Néolatines. In: Actes du séminaire interlatin de San Millan in la Cogolla.

2004. Vocabulaires de spécialité et lexicographie d'apprentissage en langues-cultures étrangères et maternelles (coord.). Etudes de Linguistique Appliquée 135.

2006. Langues de spécialité: variantes terminologiques de la langue portugaise Portugal et Brésil. In: Actes du Colloque Cette Terre Brésilienne/Esta Terra Brasileira. Lyon: Université Lumière - Lyon 2.

2006. Contextes et néologie terminologique dans le domaine médical. In: Actes des Journées Scientifiques "Mots, Termes et Contextes". Bruxelles: Réseau Lexicologie, terminologie et Traduction.

Honoré Champion.

; PRUVOST, J. 2003. Mots et Lexiculture - Hommage à Robert Galisson (coord.). Paris: 2007. Néologie et polysémie dans la terminologie médicale. In: Actes Mots de la Santé. Lyon: Université Lumière - Lyon 2.

; MEDINA, D.; MOREIRA, J. D.; CHICUNA, A. 2007. Rede de Neologia e de Terminologia em Língua Portuguesa (em situação de contacto de Línguas). In: Actas do Encontro da Associação das Universidades de Lingua Portuguesa. Praia: Cabo Verde.

MARTINS, S. 2005. O comportamento das siglas e dos acrónimos em textos de economia. Tese (Mestrado). Universidade Nova de Lisboa.

MENDES, I. 1994. O léxico do português em Mocambique. Aspectos neológicos e terminológicos. Tese (Mestrado). Universidade Nova de Lisboa.

2005. Terminologias em Moçambique. Terminómetro - A terminologia em Portugal e nos países de lingua portuguesa em África, número especial, União Latina. p. 83. Nova de Lisboa.

2009. Da neologia ao dicionário. O caso do Português de Moçambique. Lisboa: Universidade

OLIVEIRA, I. 2005a. Nature et fonctions de la métaphore dans la terminologie médicale. Étude comparée du français et du portugais. Thèse (Doctorat). Lyon: Université Lumière - Lyon 2.

2005b. Les métaphores en cardiologie, CD-Rom. Lyon / Lisboa: Université Lumière Lyon 2. Universidade Nova de Lisboa.

2006. Pour une approche de la métaphore terminologique. Banque des mots 72.

2009. Nature et fonctions de la métaphore en science. L'exemple de la cardiologie. Paris: l'Harmattan.

QUEMADA, B. 1990. Lexicographie. Lexicon der Romanistischen Linguistik (LRL) v. I. Tubingen: Max Niemeyer.

SCANTAMBURLO, L. 1999. Dicionário do guineense. Lisboa: Colibri. v. I.

SILVA; R.; COSTA, R.; FERREIRA. F. 2004. Entre langue générale et langue de spécialité: une question de collocations. Etudes de Linguistique Appliquée 135. 347-59. 
2004. Dynamique dénominative et productivité morphologique en imagerie médicale". In: Actes du Colloque la Mesure des Mots - Hommage à Philippe Thoiron. Lyon: Université Lumière Lyon 2.

TAVARES, Alice. 2009. As colocaçoes nominais de base metafórica no domínio da economia. Tese (Mestrado). Universidade Nova de Lisboa.

SILVA FILHO, S. C. 2006. Dicionário contextual da toxicodependência: a polissemia nos neologismos técnicos e científicos. Tese (Mestrado). Universidade Nova de Lisboa. 